\title{
Evaluation of Resistance of Rice Genotypes (Derived from the Cross between HKR-47 and IRBB-60) against Bacterial Blight caused by Xanthomonas oryzae pv. oryzae
}

\author{
Kirti Mehta*, Nikita Baliyan, Rahul Kumar Meena and Shikha Yashveer \\ Department of Molecular Biology, Biotechnology and Bioinformatics, College of Basic \\ Science and Humanities, Chaudhary Charan Singh Haryana Agricultural University, Hisar- \\ 125004, India
}

*Corresponding author

\section{A B S T R A C T}

\begin{tabular}{|c|}
\hline Keywords \\
\hline $\begin{array}{l}\text { Xanthomonas } \\
\text { oryzae pv. oryzae, } \\
\text { bacterial blight, } \\
\text { resistance genes, } \\
\text { disease scoring, rice }\end{array}$ \\
\hline Article Info \\
\hline $\begin{array}{l}\text { Accepted: } \\
24 \text { August } 2019 \\
\text { Available Online: } \\
\text { 10 September } 2019\end{array}$ \\
\hline
\end{tabular}

India is among the topmost rice producers and consumers in the world. Rice crop is susceptible to various bacterial diseases and one such commonly known disease is Bacterial Blight (BB) caused by the pathogen Xanthomonas oryzae pv. oryzae (Xoo) and is known to severally impact rice crop yield. Rice variety HKR-47 is widely popular amongst rice farmers and consumers in Haryana because of its high yield, medium slender grains, and excellent cooking and eating qualities, however, HKR-47 exhibits less endurance to $\mathrm{BB}$. The aim of the study conducted at CCS Haryana Agricultural University was to investigate the genetic potential of $\mathrm{BC}_{3} \mathrm{~F}_{3}$ pyramided rice genotypes (cross HKR-47 x IRBB-60) having resistance genes (Xa21, xa13 and $x a 5)$. These genotypes were tested for virulence against BB under artificial conditions using Clip method of artificial inoculation. On average, five leaves per plant were inoculated and visual scoring was done after 14 days. Rating of disease reaction was based on a 0-9 scale of the standard evaluation system (SES) for rice. Rice genotypes with all three genes exhibited relatively low mean lesion length compared to single or double combinations thus establishing higher resistance of three-gene genotypes to $\mathrm{BB}$. The lines obtained in our study can be used as genetic resources for BB resistance in breeding programs that will be paving the way for an environmentally-friendly means to achieve a better disease management.

\section{Introduction}

Bacterial Blight caused by Xanthomonas oryzae pv. oryzae (Xoo) is the oldest known bacterial disease of rice (Oryza sativa L.) in Asia. It is a major pathogen that adversely impacts rice production, especially in irrigated and rainfed lowland agricultural production systems (Mew et al., 1992). BB causes yield losses ranging from $74 \%$ to $81 \%$ (Srinivasan and Gnanamanickam, 2005) in severe conditions, depending on the stage of the crop, cultivar susceptibility and the environmental conditions (Noh et al., 2007). Bacterial Blight 
can cause damage at vegetative and reproductive stages of rice plants. Xoo invades the plant through wounds or water pores. Lesions with wavy margins start from the tip of the leaf as the water pores are located at the margins of upper parts of the leaf. These water-soaked lesions enlarge in size, turn yellow and ultimately lead to the death of plant (Nino-Liu et al., 2006).

Systemic nature of the disease, lack of effective chemical control measures (Devadath, 1989) and the concern over health hazards of pesticides have limited the utilization of chemical control agents (Guillebeau, 1998). Resistance from the host plant is known to offer the most effective, economical and environmentally safe option for management of $\mathrm{BB}$ pathogen in rice (Khush et al., 1989). Long-term cultivation of rice varieties carrying a single resistance gene has resulted in a significant shift in pathogenrace frequency and consequent breakdown of resistance (Mew et al., 1992). Pyramiding of multiple resistance genes in the background of modern high yielding varieties is a tangible solution to resistance breakdown.

Gene pyramiding aims to assemble desirable genes from multiple parents into a single genotype. It provides a broad-spectrum resistance which is an economical and effective method for BB management (Babujee and Gnanamanickam, 2000). Major resistance genes, such as $\mathrm{Xa4}, \mathrm{xa5}, \mathrm{Xa7}, \mathrm{xal3}$ and $X a 21$ have been incorporated into rice cultivars, in order to develop new resistant varieties (Perumalsamy et al., 2010). Most of these genes follow the classic gene-for-gene concept for the race-specific interaction between rice and Xoo (Flor, 1971). Some resistance genes are effective only in adult plants, while others are effective at all stages of growth. Xa21 mediated resistance gene expressed resistance at the seedling stage whereas $x a 5$ and $\mathrm{Xa4}$ gene could confer resistance at all growth stages (Adhikari et al., 1995; Garris et al., 2003; Arif et al., 2008). Some genes confer resistance to a broad spectrum of Xoo races, whereas others do so against only one or a few races. e.g. $x a 5$ and $\mathrm{Xa4}$ gene could confer broad spectrum of resistance to Xoo isolates whereas xal3 gene shows broad resistance only in adult plants (Sidhu et al., 1978). The probability of simultaneous pathogen mutations for virulence to defeat two or more effective genes is much lower than with a single gene (Mundt, 1990) and thus this study aims to establish the effectiveness of multiple resistance genes against BB.

\section{Materials and Methods}

The study material consisted of $\mathrm{BB}$ resistance genes pyramided $\mathrm{BC}_{3} \mathrm{~F}_{3}$ genotypes (selected on the basis of molecular marker analysis) derived from the cross between $\mathrm{BB}$ susceptible HKR-47 (recurrent parent) and BB resistant IRBB-60 (donor parent).

\section{Collection, isolation and maintenance of Xoo isolate}

Infected rice leaves showing bacterial blight symptoms were collected from the BB infected leaves from the fields of RRS, Kaul (Figure 1 (a)). These leaves were surfacesterilized with $2 \%$ sodium hypochlorite for 1 minute and washed twice with sterile distilled water. The leaves were then cut into $0.5 \mathrm{~cm}$ pieces and placed in $10 \mathrm{ml}$ of sterile distilled water. The cells were allowed to ooze from leaves into sterile water and then were streaked for single-colony isolation on PSA plates (Figure 1 (b)). Xanthomonas oryzae pv. oryzae was circular, smooth, convex, opaque and whitish yellow at first and turned straw yellow later as identified on PSA plates. Well separated colonies of the isolate were picked up and streaked on PSA media in laminar flow (Table 1). The Xoo isolate was multiplied and 
maintained on Peptone Sucrose Agar (PSA) plates kept in the growth room at $28^{\circ} \mathrm{C}$ for 72 hours. The culture so obtained was stored in the refrigerator at $4^{\circ} \mathrm{C}$. For inoculation, the inoculum was prepared by suspending the bacteria in sterile distilled water prior to the inoculation period. The absorbance value (590 $\mathrm{mm}$ ) was adjusted to 1 to give a bacterial suspension with a concentration of approximately $10^{9} \mathrm{cfu} / \mathrm{ml}$ (in log phase).

The genotypes, along with the control (uninoculated seedlings), were inoculated with the Xoo isolate. The plants were clip inoculated at the maximum tillering stage. The leaf blades were inoculated by clipping with Xoo suspension infected scissors at $3 \mathrm{~cm}$ below the leaf tips (Kauffman et al., 1973). On an average, five leaves per plant were inoculated and were regularly observed for the symptoms appearance. The disease severity was measured 14 days after inoculation (Figure 2) and rating the disease reaction was done on a 0-9 scale (Table 2) of the SES for rice (Anonymous, 1996).

\section{Disease Measurement}

Percent disease incidence (\%DI) was calculated according to (Gnanamanickam et al., 1999) formula as follows:

$\%$ Disease incidence

Total lesion length
Total leaf length

\section{Disease Scoring}

On the basis of mean lesion length, the genotypes were grouped into different categories of resistance and susceptibility using standard evaluation system (SES) developed at International Rice Research Institute (IRRI), Philippines.

\section{Results and Discussion}

The positive $\mathrm{BC}_{3} \mathrm{~F}_{3}$ lines were evaluated for their resistance to bacterial blight in the field and under net house conditions using the Xanthomonas oryzae strain isolated from the $\mathrm{BB}$ infected fields of RRS, Kaul. One hundred twenty $\mathrm{BC}_{3} \mathrm{~F}_{3}$ genotypes (Tables 3 and 4) with single or multiple type $\mathrm{BB}$ resistance genes (Xa21, xa13 and $x a 5$ ) along with the parents were evaluated for their resistance to bacterial blight in the field as well as in net house using the Xanthomonas oryzae strain. The pyramided lines along with the control were inoculated using a bacterial suspension of $10^{9}$ cells $/ \mathrm{ml}$. The ten three-gene positive $\mathrm{BC}_{3} \mathrm{~F}_{3}$ plants (lesion length range 0.50-0.90 cm) derived in the study from the cross, were found to be almost as effective against the virulent Xoo strain as the donor parent IRBB60 (mean lesion length of $0.50 \mathrm{~cm}$ ). These ten three-gene positives (Xa21, xa13 and xa5) $\mathrm{BC}_{3} \mathrm{~F}_{3}$ plants showed a mean lesion length of $0.54 \mathrm{~cm}$. On screening for $\mathrm{BB}$ resistance, the mean lesion length among positive lines varied from $0.50 \mathrm{~cm}$ to $10.30 \mathrm{~cm}$. Fifty lines having Xa21/xa13 genes (mean lesion length of $4.46 \mathrm{~cm}$ ), eight lines having Xa21/xa5 (mean lesion length of $4.60 \mathrm{~cm}$ ) and four lines having xa13/xa5 (mean lesion length of 5.1 $\mathrm{cm}$ ) were found to be resistant or moderately resistant to the $\mathrm{BB}$ disease. However, the lines having $\mathrm{Xa21}$ gene alone (mean lesion length of $5.30 \mathrm{~cm}$ ) were found to be more resistant than the lines with $x a 5$ gene alone (mean lesion length of $7.25 \mathrm{~cm}$ ) or xal3 gene alone (mean lesion length of $10.30 \mathrm{~cm}$ ) (Figure 3). The lines with two-gene combination had a higher level and broader spectrum of resistance than parental lines or lines with a single gene (Tables 4 and 5). The results indicated that the genes in combinations were more effective and durable against the pathogen than a single gene and that there is some kind of quantitative complementation with the presence of multiple resistance genes 
which have an additive effect on the overall level of resistance.

Through gene interaction and complementation, lines with pyramided genes were found to increase resistance quantitatively and provide a broader spectrum of resistance over those conferred by single genes (Yoshimura et al., 1995; Singh et al., 2001).

Furthermore, the lines having $\mathrm{Xa} 21$ resistant gene alone were found to be more resistant to $\mathrm{BB}$ disease than the lines having $x a 13$ or $x a 5$ alone. Xa21 was the most effective, followed by $x a 5$. Resistance gene $x a 13$ was the least effective against Xoo. The study conducted by Nikita et al. (2016) showed that individually, $x a 5$ and $X a 21$ were more effective resistance genes than $x a 13$. This is in agreement with those reported in our study. The locus, $\mathrm{Xa21}$, was found to confer resistance to all known Xanthomonas oryzae pv. oryzae races in India and Philipines (Khush et al., 1990 and Ikeda et al., 1990). The locus may encode a single gene product that specifies $\mathrm{Xa21}$ resistance to multiple pathogen isolates, or the locus may be composed of a cluster of tightly linked genes, each of which recognizes a unique isolate-specific determinant.
The higher lesion lengths observed in some combinations could be the result of recombination between marker locus and the target gene. This is more likely for $x a 13$ since the linked marker RG136 is $3.8 \mathrm{cM}$ away from the resistant gene as compared to pTA248 and RG556, the gene sequence based markers for $X a 21$ and $x a 5$, respectively.

With the availability of a gene based marker for xal3 (cited in Singh et al., 2011), the transfer can be done with higher precision.

Rajpurohit et al. (2010) also presented the similar results by recording disease reaction in forty $\mathrm{BC}_{2} \mathrm{~F}_{3}$ progenies of Type 3 basmati containing individual $x a 13$ and $\mathrm{Xa21}$ genes or combination of both under artificial inoculation conditions using mixture of seven Xoo isolates. Their results showed that the progenies having both the resistance genes $X a 21$ and $x a 13$ were highly resistant to BB disease than the progenies having individual resistance genes. However, progenies having xal3 gene alone were found to be more effective than the progenies having only $\mathrm{Xa21}$ gene. But in the present study, the $\mathrm{BC}_{3} \mathrm{~F}_{3}$ plants having xal3 gene alone were less effective than the plants having $\mathrm{Xa21}$ gene.

Table.1 Composition of Peptone Sucrose Agar (PSA) media

\begin{tabular}{|l|l|}
\hline Sucrose & $\mathbf{5 . 0} \mathbf{g}$ \\
\hline Sodium glutamate & $1.0 \mathrm{~g}$ \\
\hline Ferrous Sulphate & $0.25 \mathrm{~g}$ \\
\hline Yeast extract & $2.5 \mathrm{~g}$ \\
\hline Peptone & $10.0 \mathrm{~g}$ \\
\hline Agar & $15.0 \mathrm{~g}$ \\
\hline pH & 6.0 \\
\hline
\end{tabular}


Table.2 Disease rating using 0-9 scale

\begin{tabular}{|l|l|l|}
\hline Infection (\%) & Score & Host response \\
\hline $\mathbf{0}$ & 0 & Highly resistant (HR) \\
\hline$>\mathbf{1} \mathbf{- 1 0}$ & 1 & Resistant (R) \\
\hline$>\mathbf{1 0} \mathbf{- 3 0}$ & 3 & Moderately resistant (MR) \\
\hline$>\mathbf{3 0} \mathbf{- 5 0}$ & 5 & Moderately susceptible (MS) \\
\hline $\mathbf{> 5 0} \mathbf{- 7 5}$ & 7 & Susceptible (S) \\
\hline$>\mathbf{7 5}-\mathbf{1 0 0}$ & 9 & Highly susceptible (HS) \\
\hline
\end{tabular}

Table.3 Number of $\mathrm{BC}_{3} \mathrm{~F}_{3}$ plants with single or multiple resistance gene(s)

\begin{tabular}{|c|c|c|c|}
\hline $\begin{array}{l}\text { S. } \\
\text { No. }\end{array}$ & Gene combinations & $\begin{array}{l}\text { No. of } \\
\mathrm{BC}_{3} \mathrm{~F}_{3} \\
\text { plants }\end{array}$ & $\mathrm{BC}_{3} \mathbf{F}_{3}$ plants (Number Lines) \\
\hline 1 & Xa21/Xa21xa13/xa13xa5/xa5 & 10 & G1-8,12,13, 15; G2-3, 6; G3-11, 13;G5-13, 17 \\
\hline 2 & Xa21/Xa21xa13/xa13Xa5/Xa5 & 50 & $\begin{array}{l}\text { G1-1, 6, 7, 9, 16, 19,20; G2-2, 4, 5, 8, 9, 12, } \\
\text { 14, 20; G3- 1, 3, 5, 6, 7, 9, 14, 15, 16, 17, 19, } \\
\text { 20; G4-1, 2, 3, 4, 5, 9,10, 11; G5- 2, 6, 7, 10, } \\
11,12,16,18,19 ; \mathrm{G} 6-2,4,5,12,18,20\end{array}$ \\
\hline 3 & Xa21/Xa21Xa13/Xa13xa5/xa5 & 08 & G1-2; G2-11,16; G4-6, 8; G5-9, 14; G6-14 \\
\hline 4 & xa21/xa21xa13/xa13xa5/xa5 & 04 & G4-18; G5-15; G6-17, 19 \\
\hline 5 & Xa21/Xa21Xa13/Xa13Xa5/Xa5 & 27 & $\begin{array}{l}\mathrm{G} 1-3,4,5,10,14,18 ; \mathrm{G} 2-1,7,13,15,17, \\
18 ; \mathrm{G} 3-18 ; \mathrm{G} 4-7,14,16,17 ; \mathrm{G} 5-3 ; \mathrm{G} 6-1,3 \text {, } \\
6,8,9,10,11,13,15\end{array}$ \\
\hline 6 & $x a 21 / x a 21 x a 13 / x a 13 X a 5 / X a 5$ & 17 & $\begin{array}{l}\text { G1-11, 17; G2-10; G3-2, 4, 8, 12, ; G4- 12, } \\
13,15,19,20 ; \text { G5- } 1,4,5,8,20\end{array}$ \\
\hline 7 & xa21/xa21Xa13/Xa13xa5/xa5 & 04 & G2-19, G3-10, G6-7, 16 \\
\hline
\end{tabular}

Table.4 Disease reaction of $\mathrm{BC}_{3} \mathrm{~F}_{3}$ rice genotypes (containing one, two or three $\mathrm{BB}$ resistance genes) to Xanthomonas oryzae pv. oryzae (Xoo) (Nine point rating scale for scoring of bacterial blight disease)

\begin{tabular}{|l|l|l|l|l|l|l|l|l|}
\hline S.No. & $\begin{array}{l}\text { Parents and } \\
\mathbf{B C}_{\mathbf{3}} \mathbf{F}_{\mathbf{3}} \\
\text { genotypes }\end{array}$ & $\mathbf{X a 2 1}$ & $\boldsymbol{x a 1 3}$ & $\boldsymbol{x a 5}$ & $\begin{array}{l}\text { No. of R } \\
\text { genes }\end{array}$ & $\begin{array}{l}\text { Disease } \\
\text { incidence } \\
(\boldsymbol{\%})\end{array}$ & $\begin{array}{l}\text { Disease } \\
\text { rating }\end{array}$ & $\begin{array}{l}\text { Reaction } \\
\text { category }\end{array}$ \\
\hline $\mathbf{1}$ & IRBB-60 & + & + & + & 3 & 0.5 & 0 & HR \\
\hline $\mathbf{2}$ & HKR-47 & - & - & - & 0 & 76.6 & 9 & HS \\
\hline $\mathbf{3}$ & G1-1 & + & + & - & 2 & 11.0 & 3 & MR \\
\hline $\mathbf{4}$ & G1-2 & + & - & + & 2 & 15.0 & 3 & MR \\
\hline $\mathbf{5}$ & G1-3 & + & - & - & 1 & 12.5 & 3 & MR \\
\hline $\mathbf{6}$ & G1-4 & + & - & - & 1 & 10.5 & 3 & MR \\
\hline
\end{tabular}




\begin{tabular}{|c|c|c|c|c|c|c|c|c|}
\hline 7 & G1-5 & + & - & - & 1 & 13.7 & 3 & MR \\
\hline 8 & G1-6 & + & + & - & 2 & 8.7 & 1 & $\mathrm{R}$ \\
\hline 9 & G1-7 & + & + & - & 2 & 17.0 & 3 & MR \\
\hline 10 & G1-8* & + & + & + & 3 & 0.9 & 0 & HR \\
\hline 11 & G1-9 & + & + & - & 2 & 7.9 & 1 & $\mathrm{R}$ \\
\hline 12 & G1-10 & + & - & - & 1 & 11.5 & 3 & MR \\
\hline 13 & G1-11 & - & + & - & 1 & 14.4 & 3 & MR \\
\hline 14 & G1-12* & + & + & + & 3 & 0.8 & 0 & HR \\
\hline 15 & G1-13* & + & + & + & 3 & 0.7 & 0 & HR \\
\hline 16 & G1-14 & + & - & - & 1 & 37.0 & 5 & MS \\
\hline 17 & G1-15* & + & + & + & 3 & 68.0 & 0 & HR \\
\hline 18 & G1-16 & + & + & - & 2 & 13.3 & 3 & MR \\
\hline 19 & G1-17 & - & + & - & 1 & 32.0 & 5 & MS \\
\hline 20 & G1-18 & + & - & - & 1 & 30.4 & 5 & MS \\
\hline 21 & G1-19 & + & + & - & 2 & 18.9 & 3 & MR \\
\hline 22 & G1-20 & + & + & - & 2 & 12.6 & 3 & MR \\
\hline 23 & G2-1 & + & - & - & 1 & 11.7 & 3 & MR \\
\hline 24 & G2-2 & + & + & - & 2 & 7.0 & 1 & $\mathrm{R}$ \\
\hline 25 & G2-3* & + & + & + & 3 & 0.8 & 0 & HR \\
\hline 26 & G2-4 & + & + & - & 2 & 13.6 & 3 & MR \\
\hline 27 & $\mathrm{G} 2-5$ & + & + & - & 2 & 16.6 & 3 & MR \\
\hline 28 & G2-6* & + & + & + & 3 & 0.8 & 0 & HR \\
\hline 29 & G2-7 & + & - & - & 1 & 51.3 & 7 & $\mathrm{~S}$ \\
\hline 30 & G2-8 & + & + & - & 2 & 22.0 & 3 & MR \\
\hline 31 & G2-9 & + & + & - & 2 & 27.0 & 3 & MR \\
\hline 32 & G2-10 & - & + & - & 1 & 32.5 & 5 & MS \\
\hline 33 & G2-11 & + & - & + & 2 & 52.3 & 7 & $\mathrm{~S}$ \\
\hline 34 & G2-12 & + & + & - & 2 & 41.4 & 5 & MS \\
\hline 35 & G2-13 & + & - & - & 1 & 11.5 & 3 & MR \\
\hline 36 & G2-14 & + & + & - & 2 & 12.6 & 3 & MR \\
\hline 37 & G2-15 & + & - & - & 1 & 9.8 & 1 & $\mathrm{R}$ \\
\hline 38 & G2-16 & + & - & + & 2 & 14.2 & 3 & MR \\
\hline 39 & G2-17 & + & - & - & 1 & 8.6 & 1 & $\mathrm{R}$ \\
\hline 40 & G2-18 & + & - & - & 1 & 17.2 & 3 & MR \\
\hline 41 & G2-19 & - & - & + & 1 & 33.5 & 5 & MS \\
\hline 42 & G2-20 & + & + & - & 2 & 10.9 & 3 & MR \\
\hline 43 & G3-1 & + & + & - & 2 & 12.6 & 3 & MR \\
\hline 44 & G3-2 & - & + & - & 1 & 31.7 & 5 & MS \\
\hline 45 & G3-3 & + & + & - & 2 & 12.9 & 3 & MR \\
\hline 46 & G3-4 & - & + & - & 1 & 13.6 & 3 & MR \\
\hline 47 & G3-5 & + & + & - & 2 & 13.9 & 3 & MR \\
\hline 48 & G3-6 & + & + & - & 2 & 17.2 & 3 & MR \\
\hline 49 & G3-7 & + & + & - & 2 & 8.3 & 1 & $\mathrm{R}$ \\
\hline 50 & G3-8 & - & + & - & 1 & 14.4 & 3 & MR \\
\hline 51 & G3-9 & + & + & - & 2 & 14.9 & 1 & MR \\
\hline 52 & G3-10 & - & - & + & 1 & 15.9 & 3 & MR \\
\hline 53 & G3-11* & + & + & + & 3 & 0.7 & 0 & HR \\
\hline
\end{tabular}




\begin{tabular}{|c|c|c|c|c|c|c|c|c|}
\hline 54 & G3-12 & - & + & - & 1 & 14.9 & 3 & MR \\
\hline 55 & G3-13* & + & + & + & 3 & 0.8 & 0 & HR \\
\hline 56 & G3-14 & + & + & - & 2 & 9.2 & 1 & $\mathrm{R}$ \\
\hline 57 & G3-15 & + & + & - & 2 & 13.6 & 3 & MR \\
\hline 58 & G3-16 & + & + & - & 2 & 6.9 & 1 & $\mathrm{R}$ \\
\hline 59 & G3-17 & + & + & - & 2 & 8.3 & 1 & $\mathrm{R}$ \\
\hline 60 & G3-18 & + & - & - & 1 & 12.9 & 3 & MR \\
\hline 61 & G3-19 & + & + & - & 2 & 7.9 & 1 & $\mathrm{R}$ \\
\hline 62 & G3-20 & + & + & - & 2 & 8.6 & 1 & $\mathrm{R}$ \\
\hline 63 & G4-1 & + & + & - & 2 & 13.3 & 3 & MR \\
\hline 64 & G4-2 & + & + & - & 2 & 9.1 & 1 & $\mathrm{R}$ \\
\hline 65 & G4-3 & + & + & - & 2 & 13.7 & 3 & MR \\
\hline 66 & G4-4 & + & + & - & 2 & 6.3 & 1 & $\mathrm{R}$ \\
\hline 67 & G4-5 & + & + & - & 2 & 12.7 & 3 & MR \\
\hline 68 & G4-6 & + & - & + & 2 & 12.2 & 3 & MR \\
\hline 69 & G4-7 & + & - & - & 1 & 7.9 & 1 & $\mathrm{R}$ \\
\hline 70 & G4-8 & + & - & + & 2 & 13.4 & 3 & MR \\
\hline 71 & G4-9 & + & + & - & 2 & 13.6 & 3 & MR \\
\hline 72 & G4-10 & + & + & - & 2 & 17.9 & 3 & MR \\
\hline 73 & G4-11 & + & + & - & 2 & 16.6 & 3 & MR \\
\hline 74 & G4-12 & - & + & - & 1 & 33.9 & 5 & MS \\
\hline 75 & G4-13 & - & + & - & 1 & 34.5 & 5 & MS \\
\hline 76 & G4-14 & + & - & - & 1 & 8.2 & 1 & $\mathrm{R}$ \\
\hline 77 & G4-15 & - & + & - & 1 & 31.9 & 5 & MS \\
\hline 78 & G4-16 & + & - & - & 1 & 8.4 & 1 & $\mathrm{R}$ \\
\hline 79 & G4-17 & + & - & - & 1 & 5.3 & 1 & $\mathrm{R}$ \\
\hline 80 & G4-18 & - & + & + & 2 & 12.3 & 3 & MR \\
\hline 81 & G4-19 & - & + & - & 1 & 36.2 & 5 & MS \\
\hline 82 & G4-20 & - & + & - & 1 & 35.9 & 5 & MS \\
\hline 83 & G5-1 & - & + & - & 1 & 30.2 & 5 & MS \\
\hline 84 & G5-2 & + & + & - & 2 & 11.9 & 3 & MR \\
\hline 85 & G5-3 & + & - & - & 1 & 3.9 & 1 & $\mathrm{R}$ \\
\hline 86 & G5-4 & - & + & - & 1 & 13.6 & 3 & MR \\
\hline 87 & G5-5 & - & + & - & 1 & 19.9 & 3 & MR \\
\hline 88 & G5-6 & + & + & - & 2 & 18.6 & 3 & MR \\
\hline 89 & G5-7 & + & + & - & 2 & 11.4 & 1 & MR \\
\hline 90 & G5-8 & - & + & - & 1 & 35.3 & 5 & MS \\
\hline 91 & G5-9 & + & - & + & 2 & 18.5 & 3 & MR \\
\hline 92 & G5-10 & + & + & - & 2 & 11.3 & 1 & MR \\
\hline 93 & G5-11 & + & + & - & 2 & 13.8 & 1 & MR \\
\hline 94 & G5-12 & + & + & - & 2 & 12.5 & 1 & MR \\
\hline 95 & G5-13* & + & + & + & 3 & 0.6 & 0 & HR \\
\hline 96 & G5-14 & + & - & + & 2 & 11.9 & 3 & MR \\
\hline 97 & G5-15 & - & + & + & 2 & 17.2 & 3 & MR \\
\hline 98 & G5-16 & + & + & - & 2 & 14.5 & 3 & MR \\
\hline
\end{tabular}




\begin{tabular}{|l|l|l|l|l|l|l|l|l|}
\hline $\mathbf{9 9}$ & G5-17* & + & + & + & 3 & 5.5 & 0 & HR \\
\hline $\mathbf{1 0 0}$ & G5-18 & + & + & - & 2 & 13.5 & 3 & MR \\
\hline $\mathbf{1 0 1}$ & G5-19 & + & + & - & 2 & 7.8 & 1 & R \\
\hline $\mathbf{1 0 2}$ & G5-20 & - & + & - & 1 & 8.4 & 1 & R \\
\hline $\mathbf{1 0 3}$ & G6-1 & + & - & - & 1 & 9.4 & 1 & R \\
\hline $\mathbf{1 0 4}$ & G6-2 & + & + & - & 2 & 11.2 & 3 & MR \\
\hline $\mathbf{1 0 5}$ & G6-3 & + & - & - & 1 & 10.9 & 3 & MR \\
\hline $\mathbf{1 0 6}$ & G6-4 & + & + & - & 2 & 11.9 & 3 & MR \\
\hline $\mathbf{1 0 7}$ & G6-5 & + & + & - & 2 & 13.4 & 3 & MR \\
\hline $\mathbf{1 0 8}$ & G6-6 & + & - & - & 1 & 15.6 & 3 & MR \\
\hline $\mathbf{1 0 9}$ & G6-7 & - & - & + & 1 & 32.8 & 5 & MS \\
\hline $\mathbf{1 1 0}$ & G6-8 & + & - & - & 1 & 12.5 & 3 & MR \\
\hline $\mathbf{1 1 1}$ & G6-9 & + & - & - & 1 & 13.6 & 3 & MR \\
\hline $\mathbf{1 1 2}$ & G6-10 & + & - & - & 1 & 14.4 & 3 & MR \\
\hline $\mathbf{1 1 3}$ & G6-11 & + & - & - & 1 & 15.9 & 3 & MR \\
\hline $\mathbf{1 1 4}$ & G6-12 & + & + & - & 2 & 16.2 & 3 & MR \\
\hline $\mathbf{1 1 5}$ & G6-13 & + & - & - & 1 & 12.6 & 3 & MR \\
\hline $\mathbf{1 1 6}$ & G6-14 & + & - & + & 2 & 12.6 & 3 & MR \\
\hline $\mathbf{1 1 7}$ & G6-15 & + & - & - & 1 & 12.9 & 3 & MR \\
\hline $\mathbf{1 1 8}$ & G6-16 & - & - & + & 1 & 30.5 & 5 & MS \\
\hline $\mathbf{1 1 9}$ & G6-17 & - & + & + & 2 & 14.0 & 3 & MR \\
\hline $\mathbf{1 2 0}$ & G6-18 & + & + & - & 2 & 15.9 & 3 & MR \\
\hline $\mathbf{1 2 1}$ & G6-19 & - & + & + & 2 & 16.7 & 3 & MR \\
\hline $\mathbf{1 2 2}$ & G6-20 & + & + & - & 2 & 14.5 & 3 & MR \\
\hline
\end{tabular}

$*$ indicates three-gene positive genotypes

Table.5 Categorizing the number of $\mathrm{BC}_{3} \mathrm{~F}_{3}$ genotypes to $\mathrm{BB}$ disease response using $0-9$ scale of disease rating

\begin{tabular}{|l|l|l|l|l|}
\hline Infection (\%) & Score & Host response & $\begin{array}{l}\text { Range of \% leaf area } \\
\text { infected }\end{array}$ & $\begin{array}{l}\text { Number of } \\
\text { plants }\end{array}$ \\
\hline $\mathbf{0}$ & 0 & Highly resistant (HR) & $0.6-0.9$ & 11 \\
\hline$>\mathbf{1} \mathbf{- 1 0}$ & 1 & Resistant (R) & $3.9-9.8$ & 21 \\
\hline$>\mathbf{1 0} \mathbf{- 3 0}$ & 3 & Moderately resistant (MR) & $10.5-27$ & 67 \\
\hline $\mathbf{> 3 0} \mathbf{- 5 0}$ & 5 & Moderately susceptible (MS) & $30.4-41.4$ & 20 \\
\hline$>\mathbf{5 0} \mathbf{- 7 5}$ & 7 & Susceptible (S) & $51.3-52.3$ & 2 \\
\hline$>\mathbf{7 5}-\mathbf{1 0 0}$ & 9 & Highly susceptible (HS) & 76.6 & 1 \\
\hline
\end{tabular}


Fig.1 (a) Bacterial Blight infected leaves;

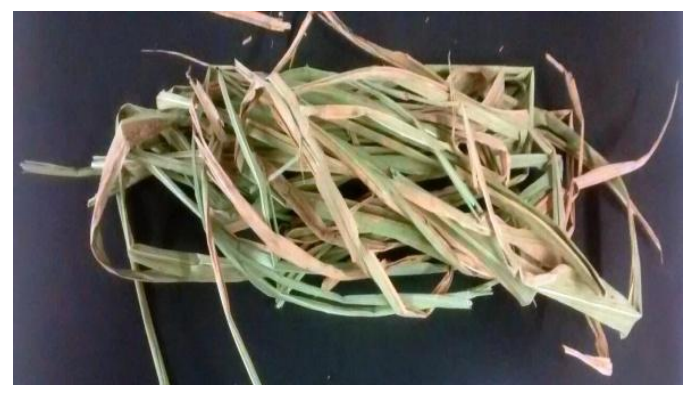

(b) Purified culture of Xanthomonas oryzae pv. oryzae on PSA medium

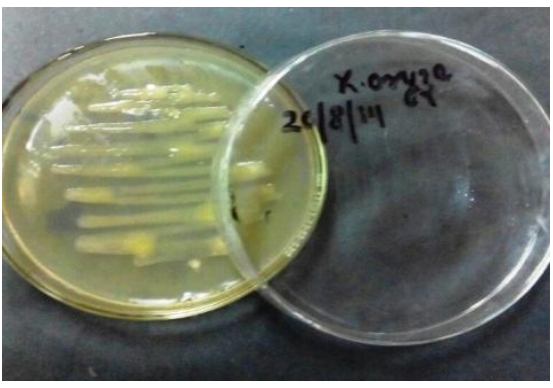

Fig.2 Disease scoring after 14 days of inoculation (a) Highly Susceptible genotype (b) Highly Resistant genotype

(a)

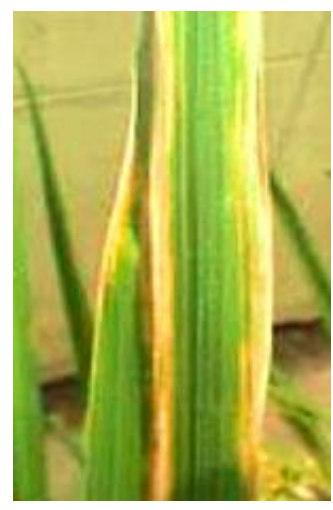

(b)

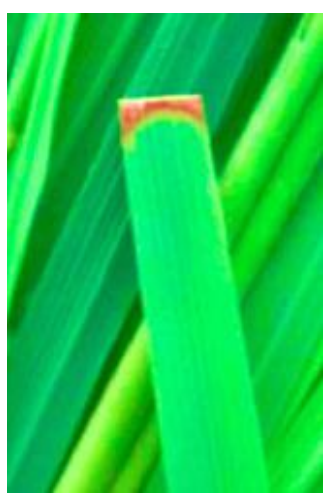

Fig.3 Disease reaction of the donor parent, susceptible parent and pyramid lines $(X a 21, x a 13$ and $x a 5)$

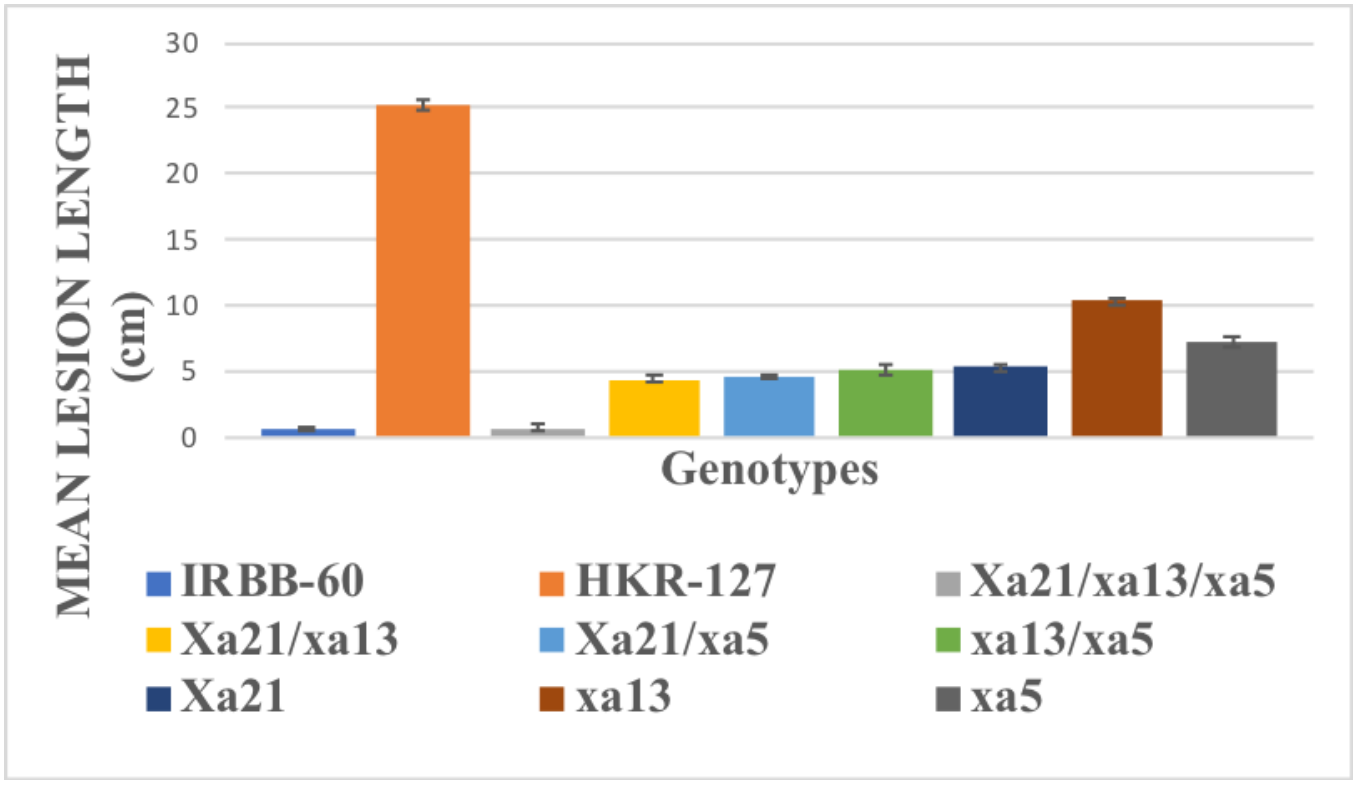




\section{References}

Adhikari, T.B., Vera Cruz, C.M., Zhang, Q., Nelson, R.J., Skinner, D.Z., Mew, T.W. and Leach, J.E. (1995). Genetic diversity of Xanthomonas oryzae pv. oryzae in Asia. Applied Microbiology and Biotechnology 61: 966-971.

Anonymous. Standard Evaluation System for Rice. INGER Genetic Resources Centre, IRRI, Manila, Philippines (1996); 4: 20-21.

Arif, M., Jaffar, M., Babar, M. and Sheikh, A.M. (2008). Identification of bacterial blight resistance genes $\mathrm{Xa} 4$ in Pakistani rice germplasm using PCR. African Journal of Biotechnology 7: 541-545.

Babujee, L. and Gnanamanickam, S.S. (2000). Molecular tools for characterization of rice blast pathogen, Magnaporthe grisea, population and molecular marker-assisted breeding for disease resistance. Current Science 78: 248257.

Devadath, S. (1989). Chemical control of bacterial blight of rice. In: Proceedings of the International Workshop on Bacterial Blight of Rice [International Rice Research Institute (ed.)], 14th18th March 1988, IRRI, Manila, Philippines. p. 89-98.

Flor, H.H. (1971). Current status of the genefor-gene concept. Annual Review of Phytopathology 9: 275-276.

Garris, A.J., McCouch, S.R. and Kresovich, S. (2003). Population structure and its effect on haplotype diversity and linkage disequilibrium surrounding the xa5 locus of rice (Oryza sativa L.). Genetics 165: 759-769.

Gnanamanickam, S.S., Priyadarisini, V.B., Narayanan, N.N., Vasudevan, P. and Kavitha, S. (1999). An overview of bacterial blight disease of rice and strategies for its management. Centre for Advanced Studies in Botany, University of Madras, Guindy Campus, Chennai 600 025, India. Current Science 77(11): 1435-1444.

Guillebeau, P. (1998). What to do about the food quality protection act? Or how can we protect the pesticides we need? Proceedings of the annual convention, Southeastern Pecan Growers' 91: 65-69.

Kauffman, H.E., Reddy, A.P.K., Hsien, S.P.Y. and Merca, S.D. (1973). An improved technique for evaluating resistance of rice varieties to Xanthomonas oryzae. Plant Disease Response 570: 537-541.

Khush, G.S., Mackill, D.J. and Sidhu, G.S. (1989). Breeding rice for resistance to bacterial blight. In Bacterial blight of rice, Proceedings of the International Workshop on Bacterial blight of Rice. International Rice Research Institute, Manila, Philippines pp. 177-207.

Khush, G.S., Bacalangco, E., and Ogawa, T. (1990). A new gene for resistance to bacterial blight from $O$. Longistaminata. Rice Genetics Newsletter 7: 121-122.

Mew, T.W., Vera Cruz, C.M. and Medalla, E.S. (1992). Changes in race frequency of Xanthomonas oryzae pv. oryzae in response to the planting of rice cultivars in the Philippines. Plant Disease 76: 1029-1032.

Mundt, C.C. (1990). Probability of mutation to multiple virulence and durability of resistance gene pyramids. Phytopathology 80: 221-223.

Nino-Liu, D.O., Ronald, P.C. and Bogdanove, A.J. (2006). Pathogen profile of Xanthomonas oryzae pathovars: model pathogens of a model crop. Molecular Plant Pathology 7: 303-324.

Noh, T.H., Lee, D.K., Park, J.C., Shim, H.K., Choi, M.Y., Kang, M.H. and Kim, J.D. (2007). Effect of bacterial leaf blight occurrence on rice yield and grain 
quality in different rice growth stage. Plant Disease 13: 20-23.

Perumalsamy, S., Bharani, M., Sudha, M. and Nagarajan, P. (2010). Functional marker-assisted selection for bacterial leaf blight resistance genes in rice (Oryza sativa L.). Plant Breeding 129: 400-406.

Rajpurohit, D., Kumar, R., Kumar, M., Paul, P., Awasthi, A.A., Basha, P.O., Puri, A., Jhang, T., Singh, K. and Dhaliwal, H.S. (2010). Pyramiding of two bacterial blight resistance and a semidwarfing gene in Type 3 Basmati using marker-assisted selection. Euphytica 178: 111-126.

Sidhu, G.S., Khush, G.S. and Mew, T.W. (1978). Genetic analysis of bacterial blight resistance in seventy four cultivars of rice, Orzo sativa L. from Indonesia. Theoretical and Applied Genetics 53: 105-111.

Singh, S., Sindhu, J.S., Huang, N., Vikal, Y., Li, Z., Brar, D.S., Dhaliwal, H.S. and Khush, G.S. (2001). Pyramiding three bacterial blight resistance genes ( $x a 5$, xal3 and Xa21) using marker-assisted selection into indica rice cultivar PR106. Theoretical and Applied
Genetics 102: 1011-1015.

Singh, A.K., Gopalakrishnan, S., Singh, V.P., Prabhu, K.V., Mohapatra, T., Singh, N.K., Sharma, T.R., Nagarajan, M., Vinod, K.K., Singh, D., Singh, U.D., Chander, S., Atwal, S.S., Seth, R., Singh, V.K., Ellur, R.K., Singh, A., Anand, D., Khanna, A., Yadav, S., Goel, N., Singh, A., Shikari, A.B., Singh, A. and Marathi, B. (2011). Marker assisted selection: a paradigm shift in Basmati breeding. Indian Journal of Genetics and Plant Breeding 71: 1-9.

Srinivasan, B. and Gnanamanickam, S. (2005). Identification of a new source of resistance in wild rice, Oryzae rufipogon to bacterial blight of rice caused by Indian strains of Xanthomonas oryzae pv. oryzae. Current Sciences 88: 25.

Yoshimura, S.A., Yoshimura, N., Iwata, McCouch, S.R., Abenes, M.L., Baraoidian, M.R., Mew, T.W. and Nelson, R.J. (1995). Tagging and combining bacterial blight resistance genes in rice using RAPD and RFLP markers. Molecular Breeding 1: 375387.

\section{How to cite this article:}

Kirti Mehta, Nikita Baliyan, Rahul Kumar Meena and Shikha Yashveer 2019. Evaluation of Resistance of Rice Genotypes (Derived from the Cross between HKR-47 and IRBB-60) against Bacterial Blight caused by Xanthomonas oryzae pv. oryzae. Int.J.Curr.Microbiol.App.Sci. 8(09): 2755-2765. doi: https://doi.org/10.20546/ijcmas.2019.809.317 